\title{
Qualified Two-Hybrid Techniques by DWT Output to Predict Fault Location
}

\author{
Azriyenni Azhari Zakri', Syukri Darmawan', Sandy Ahmad', Mohd Wazir Mustafa', Jafaru Usman \\ ${ }^{1}$ Department of Electrical Engineering, Faculty of Engineering, Universitas Riau, Pekanbaru, Indonesia \\ ${ }^{2}$ School of Electrical Engineering, Faculty of Engineering, Universiti Teknologi Malaysia, Johor Bahru, Malaysia \\ ${ }^{3}$ Department of Electrical \& Electronic Engineering, Faculty of Engineering, University of Maiduguri Borno State, \\ Nigeria
}

\begin{tabular}{|c|c|}
\hline Article Info & ABSTRACT \\
\hline $\begin{array}{l}\text { Article history: } \\
\text { Received November } 11,2019 \\
\text { Revised October } 29,2020 \\
\text { Accepted December } 21,2020\end{array}$ & \multirow{3}{*}{$\begin{array}{l}\text { The power transmission system is essential for the power scheme to transfer } \\
\text { the energy from generators to consumers. The short circuit problem repeatedly } \\
\text { occurs in the transmission system, and the main problem is to separate the } \\
\text { sources from users. This research has applied two hybrid techniques to predict } \\
\text { fault location. The first hybrid technique has involved the Discrete Wavelet } \\
\text { Transformation (DWT) and Adaptive Neuro-Fuzzy Inference System } \\
\text { (ANFIS), while the second hybrid technique is for DWT grouping and Support } \\
\text { Vector Machine (SVM). These hybrid techniques are intended to estimate the } \\
\text { fault location of each fault category in a transmission system. The DWT was } \\
\text { applied to both D8 and D9 level at the } 50 \mathrm{kHz} \text { sample frequency. The root } \\
\text { mean square (RMS) values of the D8 and D9 coefficients were used for } \\
\text { training using ANFIS and SVM techniques. After that, ANFIS and SVM were } \\
\text { utilised to detect faults in the phase and ground lines. Several types of fault } \\
\text { have been simulated, i.e. fault location, fault resistance, and original point of } \\
\text { view. The RMS results from the two hybrid techniques were compared to find } \\
\text { the best results. The tests of error estimation were performed for the three bus } \\
\text { systems. The comparison of error estimation of the two methods shows that } \\
\text { both hybrid techniques can be applied to predict fault locations. } \\
\text { Copyright } \odot 2019 \text { Institute of Advanced Engineering and Science. } \\
\text { All rights reserved. }\end{array}$} \\
\hline \multirow[t]{2}{*}{$\begin{array}{l}\text { Keywords: } \\
\text { ANFIS } \\
\text { DWT } \\
\text { estimate } \\
\text { fault } \\
\text { SVM }\end{array}$} & \\
\hline & \\
\hline \multicolumn{2}{|l|}{ Corresponding Author: } \\
\hline \multicolumn{2}{|c|}{$\begin{array}{l}\text { Azriyenni Azhari Zakri, } \\
\text { Department of Electrical Engineering, } \\
\text { Faculty of Engineering, Universitas Riau, } \\
\text { Kampus Binawidya Km 12,5 Simpang Baru Panam, Pekanbaru 28293, Indonesia } \\
\text { Email: azriyenni@eng.unri.ac.id }\end{array}$} \\
\hline
\end{tabular}

\section{INTRODUCTION}

The transmission system is the electrical power energy element to transfer electrical power from remote generation location to distribution systems. A fault that occurs in the transmission system may disturb the power source in the delivery scheme which may shut down the customer stations [1]. The fault of a shortcircuit might happen either balanced or unbalanced [2]. Unbalanced fault involves single-phase fault to ground, dual-phase, and dual phases to ground, while a balanced fault is a three-phase fault. Some categories of shortcircuit fault have different appearances in current and voltage. Accordingly, faults that occur on the transmission system need to be identified and categorized correctly to make it easier to resolve. Implementation of Artificial Neural Networks (ANN) has been performed for the fault category as well as the fault location in the transmission line. According to Hessine's research result, using modular ANN can shorten the duration of the training and improve the accuracy of ANN for the types of faults as well as estimating the fault location [3]. It has also proposed the application of DWT and support vector machine (SVM) using a sample frequency of $50 \mathrm{kHz}$. Summing the absolute numbers of the detailed derivative at levels 8 and 9 is used with SVM. The results show that this technique is applicable in parallel transmission line $[4,5]$. The demonstration of a mixture 
performance for the grouping of short circuit faults is available from this research. The work used a combination of Discrete Wavelet Transformation (DWT) and Support Vector Machine (SVM) techniques. Wavelet Transforms (WT) compensate the Fourier Transforms (FT), which has incomplete data on the frequency domain. Signal gained from wavelet transforms is devoted to frequency and time domains [6]. However, WT is generally indecisive for the category of fault in the transmission link [4]. Essentially, DWT is more extensive than Continuous Wavelet Transformation (CWT) to transform voltage and current signal to frequency domain $[8,9]$. Previous research applied WT for the grouping of fault in equivalent transmission system. They operated DWT to take wavelet level 8 at a sample frequency of $12.5 \mathrm{kHz}$. The researchers successfully classified faults in an equivalent transmission system using the ANN method [10]. Other scientists accompanied a DWT learning through Daubechies wavelet (level 4) at a sample frequency of $200 \mathrm{kHz}$ employing a Back-propagation Neural Network (BNN). The resulted Mean Square Error (MSE) is 0.03721, while Mean Absolute Error (MAE) is 0.11952 for several faults in equivalent transmission system [11]. Alternative training similarly declared the number of absolute values of the coefficients of level 8 and 9 as SVM input [12]. The produced data by DWT were used by the SVM for classification of the fault. The SVM technique for fault prediction is associated with new intelligent methods, for example, Artificial Neural Network (ANN), Probabilistic Neural Network (PNN), then Adaptive Neural Fuzzy Inference System (ANFIS). This investigation is determined to compare ANFIS and SVM to cut D8 and D9 coefficients using DWT through mother Daubechies wavelet (level 4) at $50 \mathrm{kHz}$ sample frequencies. Root Mean Square (RMS) is derived through the D8 and D9 for training and test for fault classification for the test system in Riau, Indonesia.

\section{RESEARCH METHOD}

\subsection{DWT}

DWT can analyse various categories of fault with data gained from frequency and time domain. The DWT is beneficial in identifying numerous failures as it is sensitive to signal irregularities [13]. The wavelet transformation can be separated into two kinds: DWT and Continuous Wavelet Transforms (CWT). The CWT is the amount of indicators overtime increased by the scale and locus of wavelet utility, as in equation (1) and (2) [14]:

$$
\begin{aligned}
& C(\text { scale }, \text { position })=\int_{-\infty}^{\infty} f(t) \psi_{\text {scale, position }}(t) d t \\
& T(\text { scale,position })=\int_{-\infty}^{\infty} x(t) \psi_{\text {scale, position }}^{*}(t) d t
\end{aligned}
$$

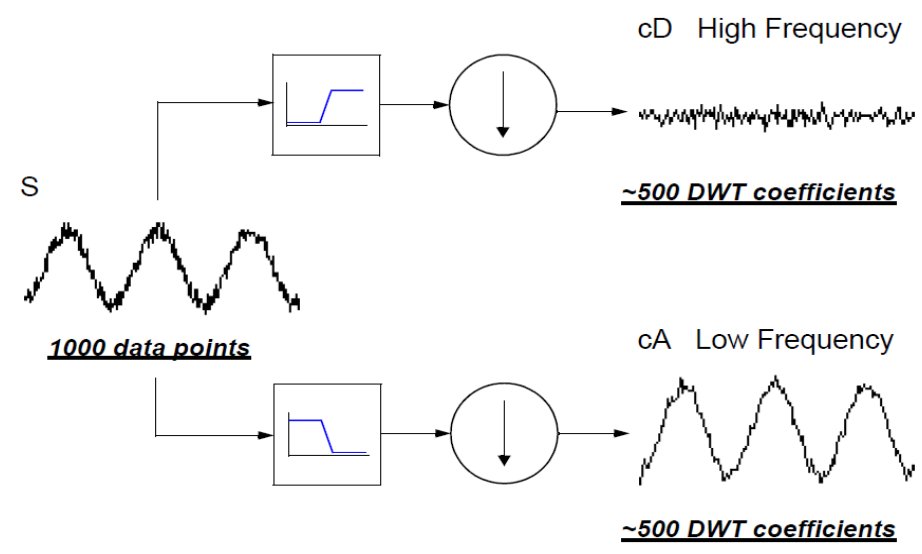

Figure 1. DWT Signal processing

CWT transforms a shifted and scaled copy of signal in the basic wavelet. As a redundant transform, CWT has wavelets overlapped and require larger computation resources to compute and store the coefficients than DWT. DWT is used to analyse wave indications correctly. The DWT determination employs the Mallat algorithm. DWT is separated in dual wave indicators, i.e., filter techniques and down-sample processes. The high-pass filter technique produces different signs through high frequency. The low-pass filters provide 
dissimilar signs through low frequency. Subsequently, the determination of the number is through downsampling operation. Thus, it only proceeds half of each data gotten previously [13]. Figure 1 shows the diagram of DWT operation. High frequency indicators remain particulars signal, and signs using low frequencies termed rough calculation. A procedure is decayed through recapitulation with a view of the information gained earlier. It will be decayed to generate separate estimates and element information. Figure 2 demonstrate the decompose repetition procedure to go for an initial wave indication. The situation will be expected to complete by summing the approximation information and element information.

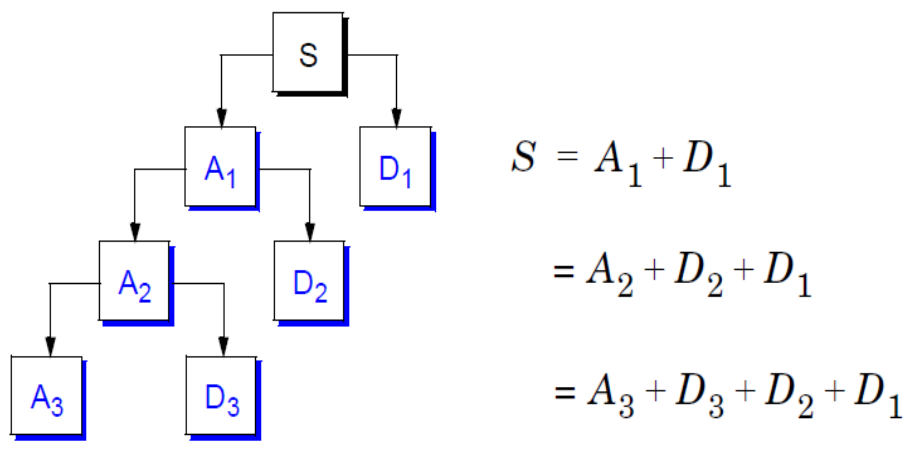

Figure 2. Repetition of DWT decomposition

In the additional decomposition procedure, the indicator can be divided on numerous low-resolution mechanisms. Therefore, the minimal frequency element filter procedure will be pursued continuously. Table 1 designates the decay of wavelet stage 9 for a cycle when the fault is sampled with frequency of $50 \mathrm{kHz}$ [12].

Table 1. The wavelet decay instruction

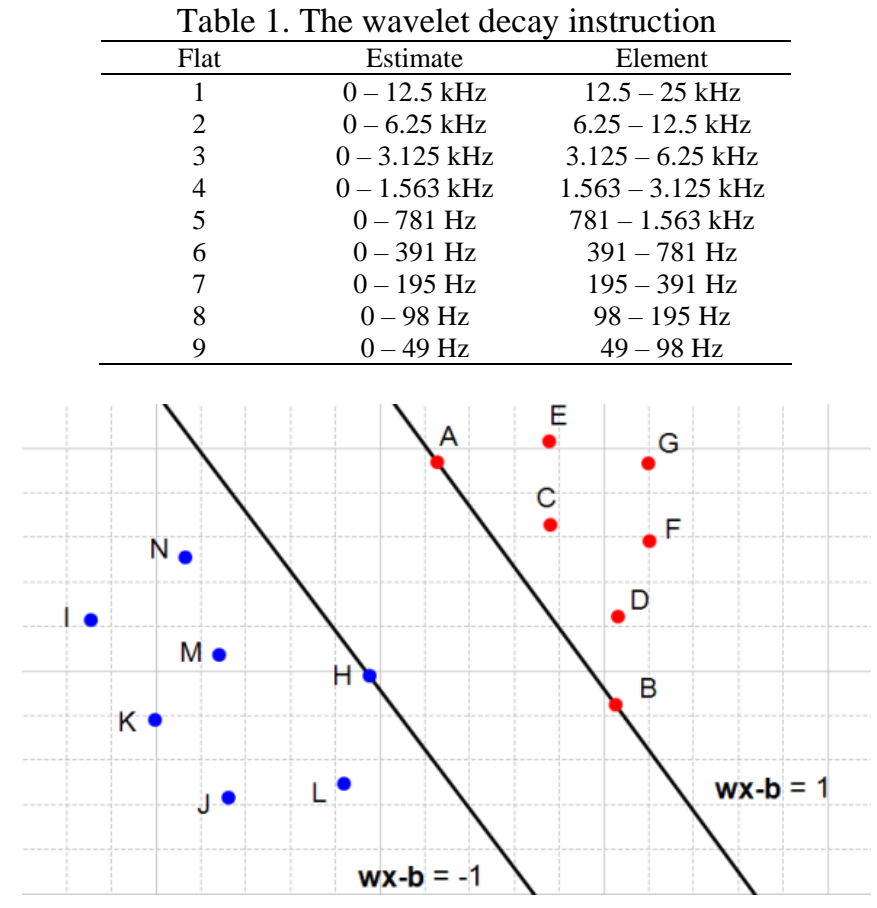

Figure 3. Equivalent planes separate two classes with SVM

\subsection{SVM}

SVM is a structure that uses a theoretical linear plane in a high-dimensional interplanetary, also proficient through procedures established on bias knowledge optimisation concept. The principal determination of this procedure creates optimum separating hyperplane, which purpose optimal parting that can continue the 
arrangement in best way. Information on the borderline field is known as a support-vector. Figure 3 shows a couple of lines separating two record groups. Also, it demonstrates the delimiter ground termed support-vector. Two categories are distributed as a result of the equivalent jumping planes. The arrangement of the midpoint is synchronised toward the Euclidean distance.

A primary delimiter field bounds the first class after the next demarcating zone over the next period, the formulation articulated in equation (3) [16]:

$$
\begin{aligned}
& \mathbf{x}_{\mathbf{i}} \mathbf{w}+b \geq 1, \mathrm{y}_{\mathrm{i}}=1 \\
& \mathbf{x}_{\mathbf{i}} \mathbf{w}+b \geq-1, \mathbf{y}_{\mathrm{i}}=-1
\end{aligned}
$$

Where $\mathbf{w}$ is a standard plane, and $b$ in another field of a usual plane. The bordering value between the bounding planes is following the formulation of space to the midpoint [17]:

$$
m=\frac{2}{\|\mathbf{w}\|}
$$

The value of this boundary will make the best use of two parameters; by increasing $b$ and $w$, its determination significantly increased. A constraint in Equation (3) is a scaling constraint by re-scaling b and w. Hence, in order to exploit $m$ equals to minimise $\|\mathbf{w}\|^{2}$. Two boundary planes on Equation (3) can be articulated using the following equation [17]:

$$
y_{i}\left(\mathbf{x}_{\mathbf{i}} \mathbf{w}+b\right) \geq 1
$$

The greatest partition of the plane is the most substantial boundary which is expressed into constraint optimisation [18]:

$$
\min \frac{1}{2}\|\mathbf{w}\|^{2}
$$

The SVM of formula was used to classify linear data using a variable called soft margin hyper-plane. Then, the best formula of separator become [17]:

$$
\begin{aligned}
& \min \frac{1}{2}\|\mathbf{w}\|^{2}+C\left(\sum_{i=1}^{n} \xi_{i}\right) \\
& \text { with, } y_{i}\left(\mathbf{x}_{\mathbf{i}} \mathbf{w}+b\right) \geq 1-\xi_{i}, \xi_{i} \geq 0
\end{aligned}
$$

Parameter $\mathrm{C}$ is used to determine inaccuracies in data grouping, and its value is assigned by user. The role of $\mathrm{C}$ is to minimize training inaccuracies and reduce complexity. The parameter C of SVM is customarily termed box constraint [17]. The proportion of accuracy is defined as [9]:

$$
\text { Classification accuracy }=\frac{\text { Accurate fault classification }}{\text { Number of sample tested }} \times 100 \%
$$

\subsection{ANFIS}

ANFIS has been developed for fault location prediction. It provided an output of the distance of the fault location. Each category of the fault has an ANFIS structure for estimating different fault locations. The simulation faults are; single phase to ground (A-G, B-G, C-G), double phase (A-B, A-C, B-C), double phase to ground (A-B-G, A-C-G, B-C-G), and three phases (A-B-C). In ANFIS, the design to estimate the fault location has been developed from various data input. The membership functions used Generalized Bell and Gaussian with three membership functions. It is designed to obtain and select better accuracy results for ANFIS training in fault location. The training process is carried out in 100 iterations. The ANFIS training was conducted with 770 input and 77 targets (each fault). The ANFIS fault classification output for each phase and ground is a condition of 1 or 0 . It can indicate condition there is a fault in each phase or ground. ANFIS approved testing of 200 input (each fault). The variations of the two membership functions performed by 
ANFIS are Generalized Bell and Gaussian. The accurate values can be calculated by comparing ANFIS with a target. The input data implemented in training are the RMS DWT value (coefficient D9) of the voltage and current for each phase post fault. As many as 200 inputs and targets performed ANFIS training for fault estimation. The output from ANFIS is the approximate point to estimate the fault location that occurs along the transmission line.

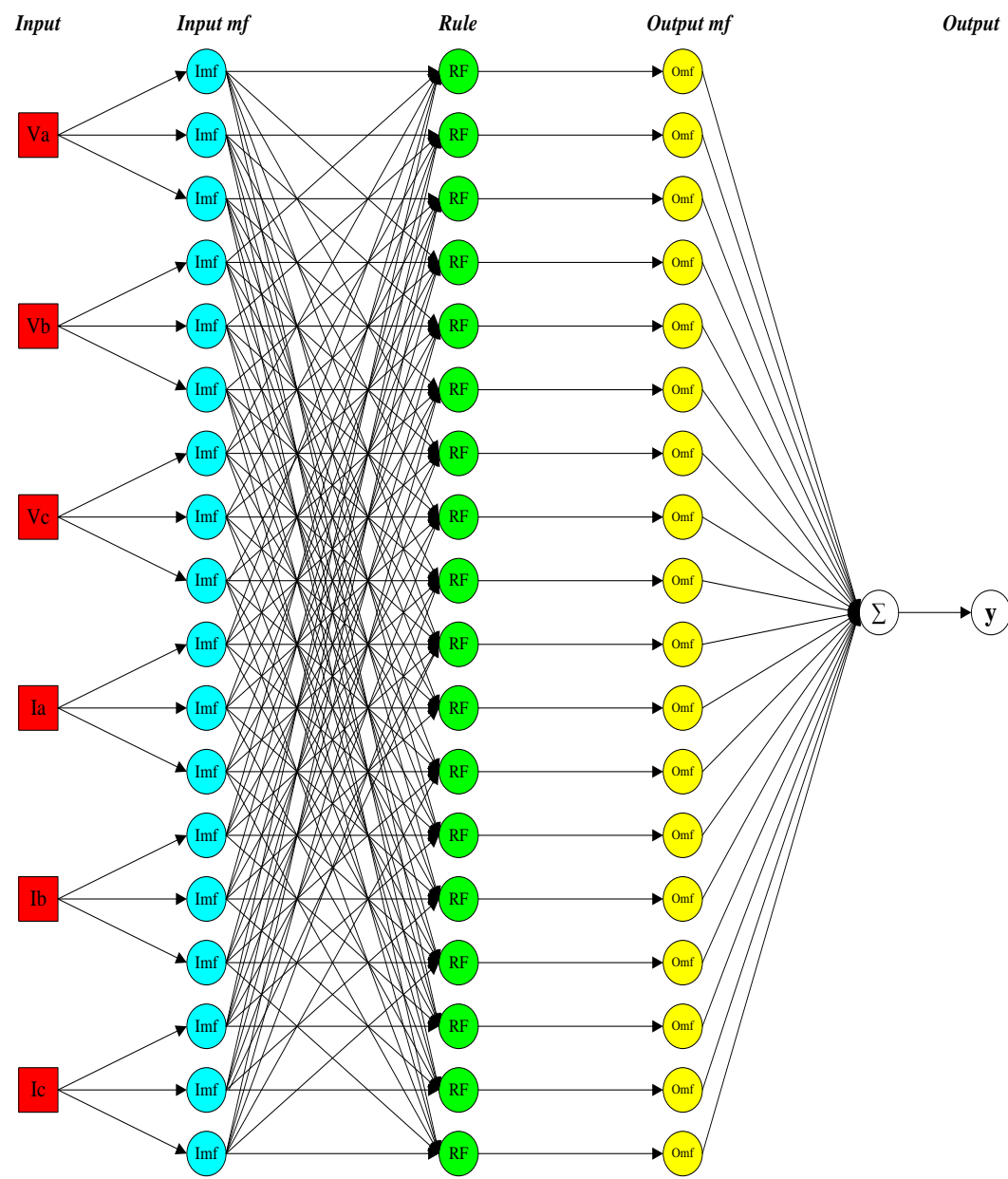

Figure 4. The structure of ANFIS developed

Figure 4 is the ANFIS network structure for estimating fault locations. The red part is the input current and voltage, and the blue part is the number of membership functions consisting of three outputs of the membership function. The production is contained in the form of the distance of the fault location. The fault location estimate is indicated by six input, which is the RMS values of the D9 coefficient of the fault voltage and current at a separate phase. Data are to estimate the fault location of ANFIS can be formulated as following:

where:

$\mathrm{X}_{\mathrm{FL}}=\left[\mathrm{VD} 9_{\mathrm{A}}, \mathrm{VD} 9_{\mathrm{B}}, \mathrm{VD} 9_{\mathrm{C}}, \mathrm{ID} 9_{\mathrm{A}}, \mathrm{ID} 9_{\mathrm{B}}, \mathrm{ID} 9_{\mathrm{C}}\right]$

$\mathrm{X}_{\mathrm{FL}} \quad$ : ANFIS input data for fault estimation

VD9 $9_{i}$ : in the RMS value on that D9 coefficient of the fault voltage

ID9 $_{\mathrm{i}} \quad$ : in the RMS value on the D9 coefficient of the fault current

$i \quad$ : Phase A, B, C

\subsection{Power System Transmission}

Figure 5 is the transmission scheme in three buses: Koto Panjang (KP), Bangkinang (BG), and Garuda Sakti (GS), all are in Riau, Indonesia. The transmission scheme is a voltage of $150 \mathrm{kV}$ with a frequency of 50 Hz. In the transmission link among the Bus KP and Bus GS, the short circuit fault occured. The substation KP consists of four power systems. The separate generator data is specified in Table 2. Subsequently, Table 3 
illustrates the power transformer constraints connected with the generator. Table 4 is the transmission link constraint engaged to separately connecting starting bus to bus. The distance of a transmission system between Bus KP to Bus GS is $64 \mathrm{~km}$, Bus KP to Bus BG is $18.19 \mathrm{~km}$, and Bus BG to GS is $46.09 \mathrm{~km}$. Each bus is placed below capacity through the constraints in Table 5 . A capacitor bank is arranged by bus to GS through a capability of 50 MVAR.

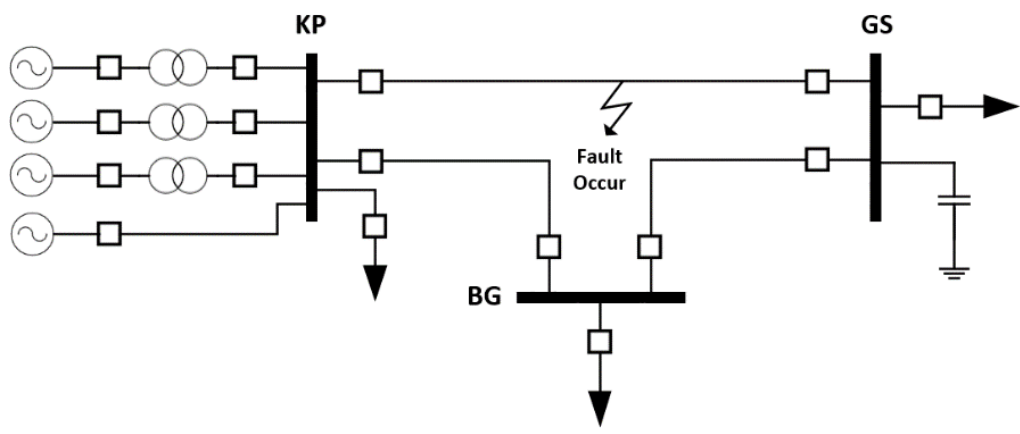

Figure 5. Single line diagram transmission scheme

Table 2. Factor of generator

\begin{tabular}{ccccc}
\hline Generator & $\begin{array}{c}\text { MVA short } \\
\text { circuit (MVA) }\end{array}$ & $\mathrm{V}_{\text {RMS }}(\mathrm{kV})$ & Frequency $(\mathrm{Hz})$ & $\mathrm{X} / \mathrm{R}$ \\
\hline $1,2,3$ & 209.25 & 11 & 50 & 13 \\
4 & 1260.85 & 150 & 50 & 5 \\
\hline
\end{tabular}

Table 3. Factor of transformer

\begin{tabular}{ccc}
\hline Parameter & $\begin{array}{c}\text { High voltage } \\
\text { side }\end{array}$ & $\begin{array}{c}\text { Low voltage } \\
\text { side }\end{array}$ \\
\hline Rate power & \multicolumn{3}{c}{$60 \mathrm{MVA}$} \\
Insignificant frequency & \multicolumn{3}{c}{$50 \mathrm{~Hz}$} \\
Appraised voltage & $150 \mathrm{kV}$ & $11 \mathrm{kV}$ \\
Leak resistance & $0.5 \mathrm{pu}$ & $0.5 \mathrm{pu}$ \\
Leak reactant & $0.5 \mathrm{pu}$ & $0.5 \mathrm{pu}$ \\
Assembly & $\mathrm{Y}$ & $\mathrm{Y}$ \\
\hline
\end{tabular}

Table 4. Factor of transmission system

\begin{tabular}{cccc}
\hline Sequence & $\begin{array}{c}\text { Resistance } \\
(\Omega / \mathrm{km})\end{array}$ & $\begin{array}{c}\text { Inductance } \\
(\Omega / \mathrm{km})\end{array}$ & $\begin{array}{c}\text { Susceptance } \\
(\mu \mathrm{S} / \mathrm{km})\end{array}$ \\
\hline Positive/Negative & 0.079 & 0.389 & $2.95 \mathrm{e}-6$ \\
Zero & 0.305 & 1.029 & $1.884 \mathrm{e}-6$ \\
\hline
\end{tabular}

Table 5. Factor of load

\begin{tabular}{ccc}
\hline Bus & $\begin{array}{c}\text { Active power } \\
(\mathrm{MW})\end{array}$ & $\begin{array}{c}\text { Reactive Power } \\
(\mathrm{MVAr})\end{array}$ \\
\hline KP & 17.95 & 5.8 \\
BG & 48.032 & 13.2 \\
GS & 114.788 & 26.9 \\
\hline
\end{tabular}

\section{RESULTS AND DISCUSSION}

The data model is run between $0.00002 \mathrm{~s}$ in separated model. When the fault happens, a single round current surge is recycled as DWT input through the number of models $1 /(10-5 * 50)=1000$ example numbers. The computer-generated fault of short-circuiting is single-phase to ground (A-G, B-G, C-G), dual-phase (A-B, A-C, B-C), dual-phase to ground (A-B-G, A-C-G, B-C-G) and three-phase (A-B-C) [20]. 3.1. Simulation System 
The constraints used for training and test data are noted in Table 6 . The fault resistance is $10 \Omega$. The quantity of models accomplished to gain the training numbers is 6930 data (10 faults $* 11$ distance of faults $* 7$ resistance of faults $* 9$ FIA). The number of models accomplished to acquire the test data is 4900 data (10 faults $* 10$ distance of faults $* 7$ resistance of faults $* 7$ FIA). The current measured on the Bus KP becomes reference for the phase to ground (AG) of a short circuit. The fault distances through different points through $10 \%$ increments, resistance of fault $35 \Omega$, then FIA $50^{\circ}$ that can be located is shown in Figure 6.

Table 6. Constraint for training and test data

\begin{tabular}{ccc}
\hline Constraint & Training data & Test data \\
\hline Fault distance $(\%)$ & $0,10,20,30,40,50,60,70,80,90,100$ & $5,15,25,35,45,55,65,75,85,95$ \\
Fault resistance $(\%)$ & $10,20,35,50,70,100,150$ & $8,25,45,65,85,110,140$ \\
Fault inception angle $\left({ }^{\circ}\right)$ & $10,20,30,40,50,60,70,80,90$ & $5,11,17,24,45,65,88$ \\
\hline
\end{tabular}

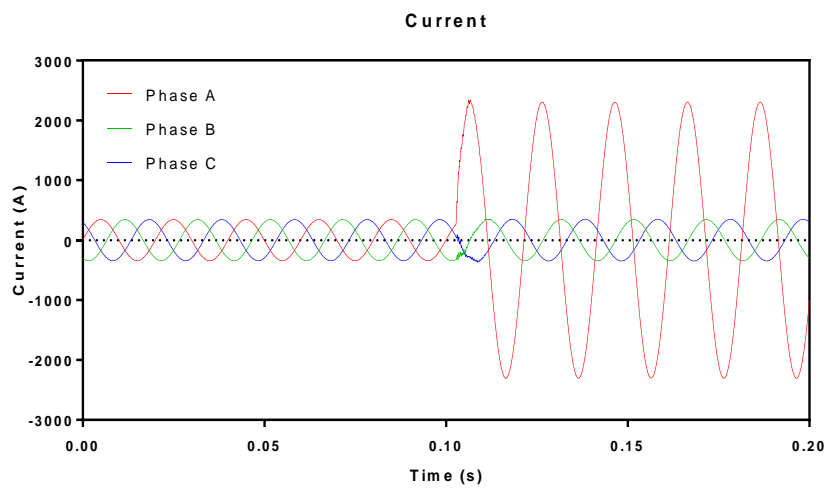

Figure 6 The fault current simulation at bus KP for one phase to ground

\subsection{Processing Data}

The fault current occured in one cycle (post-fault) was processed using mother wavelet for Daubechies level 4 (DB 4) at level 9 (D9). DB 4 is beneficial for the investigation of momentary indicators [6, 7, 10]. Figure 7 shows outcomes of signal processing using DWT procured at level 8 elements (D8) as well as element level 9 (D9). The value on D8 and D9 of instantaneous currents for a cycle after the fault happens were calculated by measuring the Root Mean Square (RMS). This RMS value was then used as input for the SVM method. Moreover, the ground current is calculated from the sum of currents of each phase divided by three as following $[2,19]$ :

$$
I_{0}=\frac{I_{a}+I_{b}+I_{c}}{3}
$$

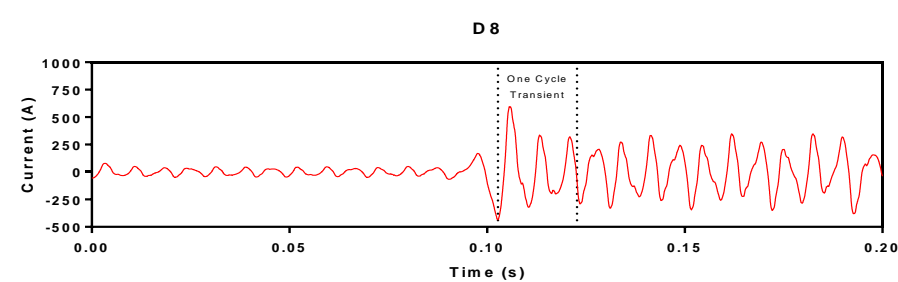

(a)

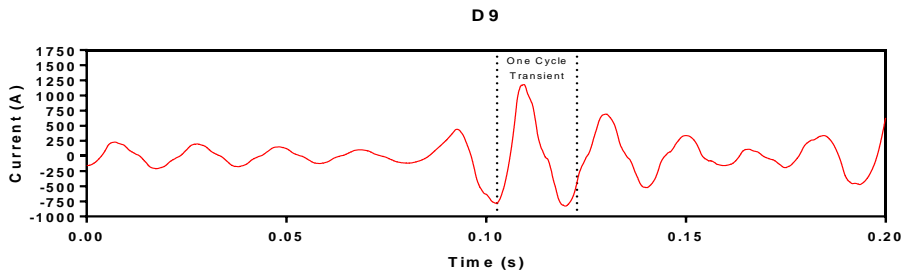

(b)

Figure 7. DWT outcomes in element at (a) D8, (b) D9 


\subsection{Estimation of Short Circuit Fault}

The ANFIS structures has been trained to estimate the A-G fault location. Table 7 demonstrates that the ANFIS structure test results have the smallest RMSE and MSE values using the Gaussian membership function (FLAG1) with values of 0.027835 and 0.022561 . The ANFIS structure that has the largest RMSE and MSE values in the ANFIS structure occurs in the generalised bell (FLAG2) membership function with a value of 0.060488 and 0.043865 .

Table 7. The ANFIS test for estimated fault location (A-G)

\begin{tabular}{ccccc}
\hline \multirow{2}{*}{ Target $(\mathrm{Km})$} & \multicolumn{2}{c}{ MF Gaussian } & \multicolumn{2}{c}{ MF Generalized Bell } \\
\cline { 2 - 5 } & Output $(\mathrm{Km})$ & Error $(\%)$ & Output $(\mathrm{Km})$ & Error $(\%)$ \\
\hline 0.768 & 0.789576 & 0.033712 & 0.809556 & 0.064932 \\
3.968 & 3.984127 & 0.025198 & 4.006951 & 0.060860 \\
7.168 & 7.207151 & 0.061173 & 7.233690 & 0.102640 \\
10.368 & 10.387577 & 0.030590 & 10.384356 & 0.025557 \\
13.568 & 13.544340 & 0.036968 & 13.390206 & 0.277803 \\
16.768 & 16.787157 & 0.029933 & 16.822199 & 0.084686 \\
19.968 & 19.946648 & 0.033363 & 19.963136 & 0.007600 \\
23.168 & 23,188102 & 0.031409 & 23.144264 & 0.037087 \\
26.368 & 26.309714 & 0.091072 & 26.291224 & 0.119963 \\
29.568 & 29.520225 & 0.074648 & 29.493028 & 0.117144 \\
32.768 & 32.746320 & 0.033876 & 32.760203 & 0.012183 \\
35.968 & 35.965673 & 0.003635 & 35.964228 & 0.005894 \\
39.168 & 39.136674 & 0.048947 & 39.106709 & 0.095767 \\
42.368 & 42.368795 & 0.001242 & 42.383853 & 0.024771 \\
45.568 & 45.573165 & 0.008071 & 45.591343 & 0.036473 \\
48.768 & 48.764256 & 0.005849 & 48.762635 & 0.008383 \\
51.968 & 51.929067 & 0.060832 & 51.892942 & 0.117278 \\
55.168 & 55.120119 & 0.074814 & 55.077923 & 0.140745 \\
58.368 & 58.362687 & 0.008302 & 58.370922 & 0.004565 \\
61.568 & 61.575299 & 0.011405 & 61.551078 & 0.026441 \\
\hline RSME & \multicolumn{2}{c}{0.060488} \\
MAE & 0.027835 & & 0.043865 \\
\hline
\end{tabular}

Table 8 is the result of error calculation for the estimated location of the fault for each type of fault that has been replicated. The fault that has been computer-generated includes; A-G, B-G, C-G, A-B, A-C, B-C, AB-G, A-C-G, B-C-G, then A-B-C. From the test, ANFIS results for estimation fault location with the smallest average error testing is generated by the ANFIS is $6.05 * 10-4 \%(\mathrm{~A}-\mathrm{G})$, while the most significant average error is produced by the ANFIS estimated fault location is $2.9 * 10-2 \%$ (A-C). The RMS element of D8 is also D9 for separate phase then ground current is recycled as contribution SVM to acquire a hyper-plane utility. Constraint SVM is involved in the limitation box constraint $C$ significance is 1 , and the kernel measure significance is 0.35. Hyper-plane established from SVM exercise expending the contribution value of exercise numbers. The SVM for approximating the fault location is given six input, namely; the RMS values of the D8 also D9 coefficients of the current signal post fault in each phase. Data of the SVM estimated fault location can be sketched as following:

a) two RMS coefficient details of the phase current signal A

b) two RMS coefficient details of the phase current signal B

c) two RMS coefficient details of the phase current signal C

Table 8. Percentage error ANFIS estimated fault location via ANFIS

\begin{tabular}{cccc}
\hline \multirow{2}{*}{ Type of fault } & \multicolumn{3}{c}{ Error $(\%)$} \\
\cline { 2 - 4 } & average value & maximum & minimum \\
\hline A-G & 0.000605 & 0.002612 & 0.000002 \\
B-G & 0.000865 & 0.003601 & 0.000016 \\
C-G & 0.001145 & 0.003001 & 0.000064 \\
A-B & 0.007382 & 0.024944 & 0.000384 \\
A-C & 0.029827 & 0.107867 & 0.000469 \\
B-C & 0.001452 & 0.005280 & 0.000026 \\
A-B-G & 0.002798 & 0.010721 & 0.000074 \\
A-C-G & 0.002586 & 0.007653 & 0.000084 \\
B-C-G & 0.001158 & 0.003627 & 0.000037 \\
A-B-C & 0.007240 & 0.015574 & 0.000133 \\
\hline
\end{tabular}


The SVM used is a Gaussian kernel type, the data for estimating fault locations are $\varepsilon, \gamma$ and box constraints (C). Table 9 is the output on the RMSE and MAE values, where the value is error limit with a fixed input value of $10^{-3}$. The gamma parameter and box constraint values are varied. It aims to get a small RMSE result and a short training duration. The constraint $\gamma$ has values $10^{-2}$ and $10^{-1}$, while the parameter $\mathrm{C}$ with values $10^{0}, 10^{1}$, $10^{2}, 10^{3}$, and $10^{4}$. The training simulations were conducted ten times.

Table 9. Average values of RSME and MAE using the SVM for estimating fault locations

\begin{tabular}{cccccc}
\hline \multirow{2}{*}{ No } & \multirow{2}{*}{ Model } & $\gamma$ & $\begin{array}{c}\text { Average of } \\
\text { RSME }\end{array}$ & Average of MAE \\
\cline { 2 - 4 } & FL11 & & 1 & 11.4767 & 9.6839 \\
2 & FL12 & \multirow{2}{*}{ Parameter SVM } & 1.2711 & 0.8940 \\
3 & FL13 & & 10 & 0.1003 & 0.0624 \\
4 & FL14 & & 100 & 0.0255 & 0.0166 \\
5 & FL15 & & 1000 & 0.0097 & 0.0060 \\
6 & FL21 & & 10000 & 8.1796 & 5.4478 \\
7 & FL22 & 0.1 & 10 & 0.7748 & 0.3567 \\
8 & FL23 & & 100 & 0.0919 & 0.0531 \\
9 & FL24 & & 1000 & 0.0241 & 0.0137 \\
10 & FL25 & & & 0.0186 & 0.0095 \\
\hline
\end{tabular}

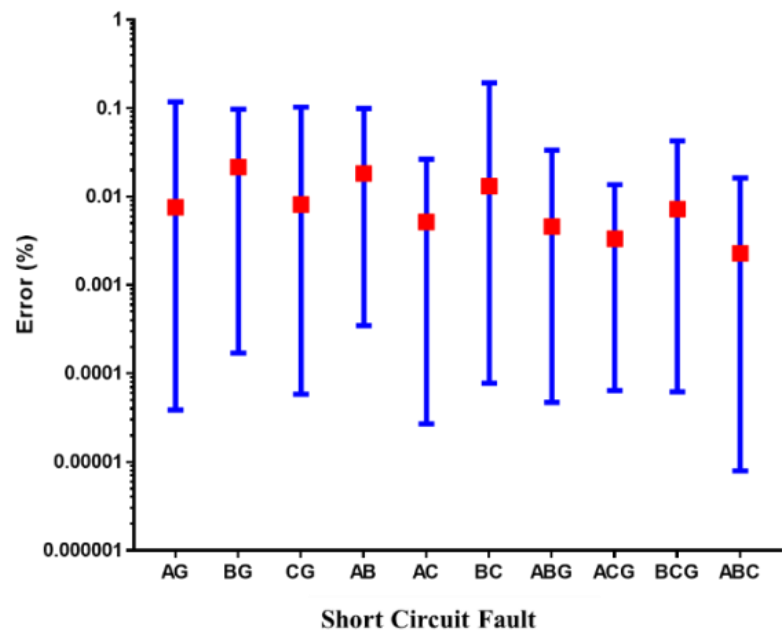

Figure 8. Percentage of the SVM accuracy approximating the location of separate fault

The best SVM models for training and testing are selected with parameters $\gamma=0.01$ and $\mathrm{C}=1000$ while the preferred SVM model for the estimated fault location is with parameters of $\gamma=0.01$ and $\mathrm{C}=10000$. Figure 8 shows the result of the SVM testing of the estimated fault location by calculating the error value of the SVM model for determining the fault location.

The test result of fault classification and fault location shows the error percentage value on each ANFIS. ANFIS fault type has determined the fault in each phase and ground correctly according to the nature of fault that occurs. Accuracy of ANFIS fault classification is $100 \%$ without any errors. The error value of ANFIS results for estimating each fault's location has been calculated, as shown in Table 9. The variation of SVM parameters for fault location estimation is presented in Table 10. It shows the average number of iterations needed to achieve the epsilon $(\varepsilon) 10^{-3}$ target and the acquisition of RMSE and MSE values during training and testing on each SVM model when an A-G fault occurs. Table 10 demonstrates that type A-G's estimated fault location has several iterations than others when the box constraint parameter increases with the same gamma value. The estimated SVM model with the smallest number of iterations is in the FLAG41 SVM model with 25 iterations, while the largest is in the FLAG26 SVM model with 106 iterations with RMSE of 0.0339 and MAE of 0.0154. On the other hand, the SVM representative with the FLAG16 SVM model has the least RMSE and MAE values with RMSE of 0.0121 and MAE of 0.0053 . 
Table 10. The result of the SVM training and testing estimates fault of A-G

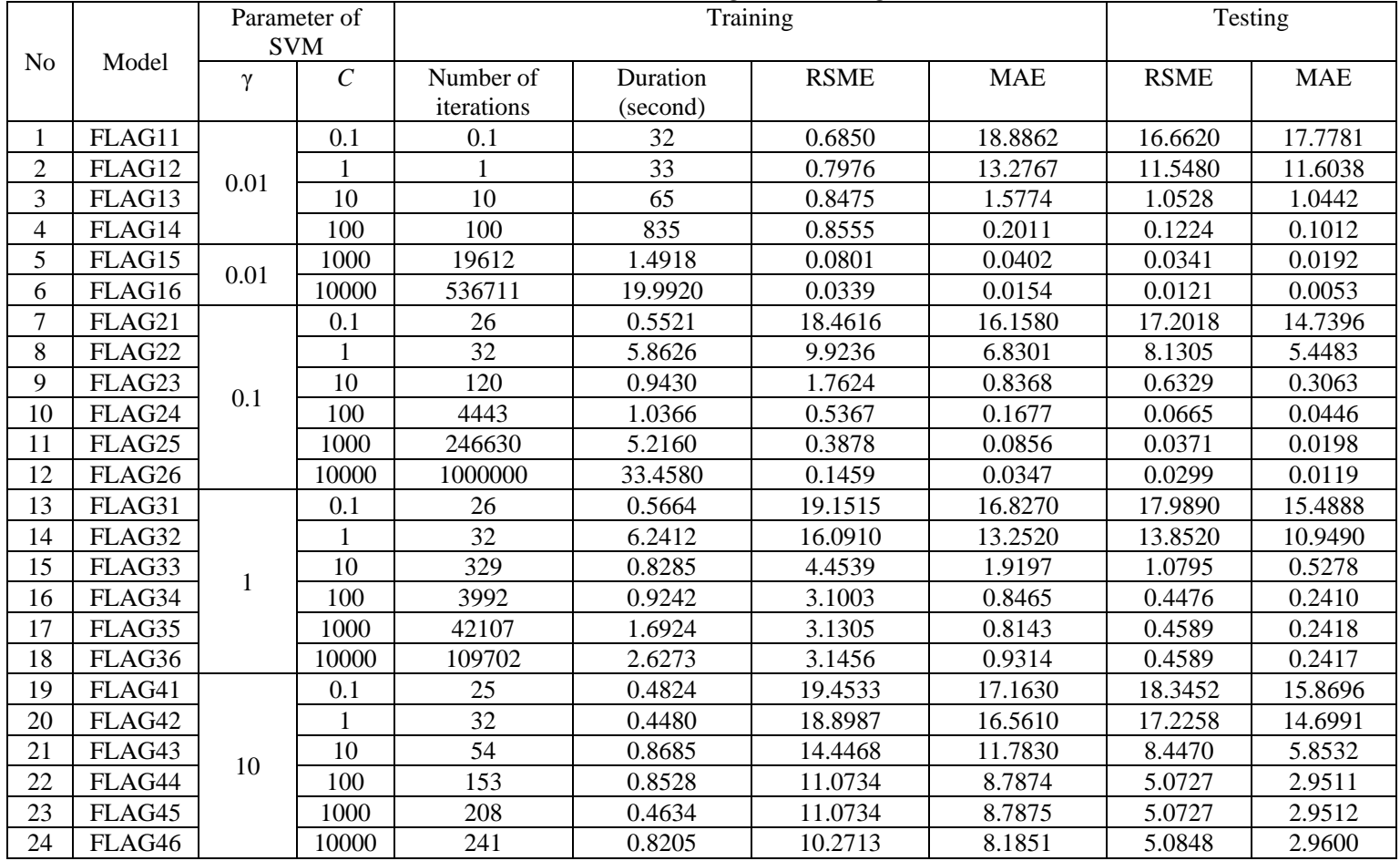

Figure 9 shows the simulation results that the minimum and maximum error range of hybrid technique one is from $2 * 10^{-6} \%$ to $0.107867 \%$, while for hybrid technique two is from $8 * 10^{-6} \%$ to $0.194868 \%$. The comparison results of the minimum and the maximum percentage of errors and the average percentage of errors for hybrid techniques one and hybrid techniques two are to prove that between these two hybrid techniques does not have significant differences in error results.

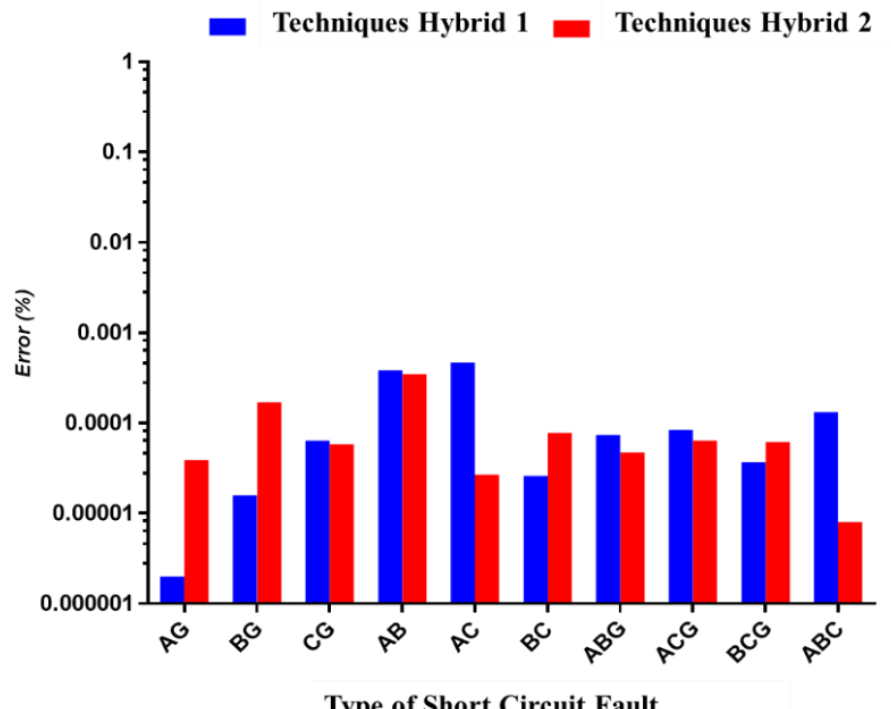

Figure 9. Comparison of the error percentage of techniques hybrid 1 and 2

\section{CONCLUSION}

In this study, the estimation of the fault location in the electric power transmission system has been carried out by simulating the classification of short circuit faults. The DWT has been applied to analyze the type of interference obtained from the frequency domain and time domain, therefore, DWT is very useful in detecting 
and processing various interference data. The results of the DWT were carried out using two techniques, namely ANFIS and SVM with training and test variables; resistance disturbance and FIA. Furthermore, the significance of the RMS value for levels D8 and D9 for the training and test data has a very small error value.

In the SVM technique there is an alternative hyperplane dividing line between two classes to find the maximum point, the closest pattern as a support vector. Then, ANFIS simulations have been trained to estimate the location of the same disturbances as was done in the SVM (A-G fault) technique. The ANFIS structure test has the smallest RMSE and MSE values using the Gaussian membership function (FLAG1) with values of $2.7835 * 10^{-2}$ and $2.2561 * 10^{-2}$. The ANFIS structure has the largest RMSE and MSE values in the ANFIS structure found in the generalized bell membership function (FLAG2), with a magnitude of $6.0488 * 10^{-2}$ and at $4.3865 * 10^{-2}$, but the values are still within tolerance limits. The design of the FL16 SVM model as an SVM approximation model was selected for each type of disturbance with a value of 0.01 and a value of 10000 resulting in the final average test error, specifically for the type of disturbance ABC $2.281 * 10^{-3} \%$ RMSE is $2.3 * 10^{-3}$, and MAE is $1.5 * 10^{-3}$. The comparison of the accuracy of the simulation results is shown in the form of percentage errors. It is found that hybrid technique one and two have a difference but insignificant in results, within the standard of fault tolerance. Finally, the simulation results of these two hybrid techniques shows that both hybrid techniques can be applied to predict the location of the disturbance with a satisfactory level of accuracy.

\section{REFERENCES}

[1] A. K. Abotsi, "Power outages and production efficiency of firms in Africa," International Journal of Energy Economics and Policy, vol. 6, no. 1, pp. 98-104, 2016.

[2] T. Gönen, Electrical Power Transmission System Engineering: Analysis and Design, 3 ed. Boca Raton: CRC Press, 2014, pp. 575-597.

[3] Hessine, M. B., \& Saber, S. B. (2014). Accurate Fault Classifier and Locator for EHV Transmission Lines Based on Artificial Neural Networks. Hindawi Publishing Corporation, 1-19.

[4] Mosavi, M., \& Tabatabei, A. (2014). Wavelet and neural network-based fault location in power systems using statistical analysis of traveling wave. Arab J Sci Eng, 8, 1-8.

[5] Azriyenni, Syukri. D, Jafaru. U, Iswadi. H.R, Boy Ihsan, "Extract Fault Signal via DWT and Penetration of SVM for Fault Classification at Power System Transmission." 2018 2nd International Conference on Electrical Engineering and Informatics (ICon EEI), pp. 191-196, 2019.

[6] A. Teolis, Computational Signal Processing with Wavelets. Boston: Birkhäuser, 2017.

[7] Z. Liu, Z. Han, Y. Zhang, and Q. Zhang, "Multiwavelet packet entropy and its application in transmission line fault recognition and classification," IEEE, vol. 25, no. 11, pp. 2043-2052, 2014.

[8] K. Chen, C. Huang, and J. He, "Fault detection, classification and location for transmission lines and distribution system: a review on the methods," High Voltage, vol. 1, no. 1, pp. 25-33, 2016.

[9] P. Ray and D. P. Mishra, "Support vector machine-based fault classification and location of a long transmission line," Engineering Science and Technology, pp. 1-13, 2016.

[10] V. S. Kale, S. R. Bhide, P. P. Bedekar, and G. V. K. Mohan, "Detection and classification of faults on parallel transmission lines using wavelet transform and neural network," International Journal of Electrical and Computer Engineering, vol. 2, no. 10, pp. 2389-2393, 2008.

[11] A. A. M. Zin, M. Saini, M. W. Mustafa, A. R. Sultan, and Rahimuddin, "New algorithm for detection and fault classification on parallel transmission line using DWT and BPNN based on Clarke's transformation," Neurocomputing, vol. 168, no. 30, pp. 983-993, 2015.

[12] Amer, "Discrete wavelet transform and support vector machine-based parallel transmission line faults classification," IEEJ Trans, vol. 11, pp. 43-48, 2016.

[13] Z. He, Wavelet Analysis and Transient Signal Processing Applications for Power Systems. Wiley, 2016.

[14] P. S. Addison, The Illustrated Wavelet Transform Handbook: Introductory Theory and Applications in Science, Engineering, Medicine and Finance, 2 ed. Boca Raton: CRC Press, 2017.

[15] M. Misiti, Y. Misiti, G. Oppenheim, and J.-M. Poggi, Wavelet Toolbox ${ }^{\text {TM }}$ Getting Started Guide. Natick: The MathWorks, Inc., 2016.

[16] M. N. Murty and R. Raghava, Support Vector Machines and Perceptrons Learning, Optimisation, Classification, and Application to Social Networks. Springer, 2016.

[17] A. Kowalczyk, Support Vector Machine Succinctly. Syncfusion, Inc., 2017. 
[18] M. N. Mahmud, M. N. Ibrahim, M. K. Osman, and Z. Hussain, "Fault classification in transmission line using support vector machine (SVM) and wavelet features," Journal of Engineering and Applied Sciences, vol. 11, no. 11, pp. 2479-2484, 2016.

[19] J. C. Das, Understanding Symmetrical Components for Power System Modeling. Hoboken: John Wiley \& Sons, Inc., 2017, pp. 15-19.

[20] Azriyenni, M.W.Mustafa, Application of ANFIS for Distance Relay Protection in Transmission Line. International Journal of Electrical and Computer Engineering (IJECE), 5(6): pp. 1311-1318, 2015.

\section{BIOGRAPHY OF AUTHORS}
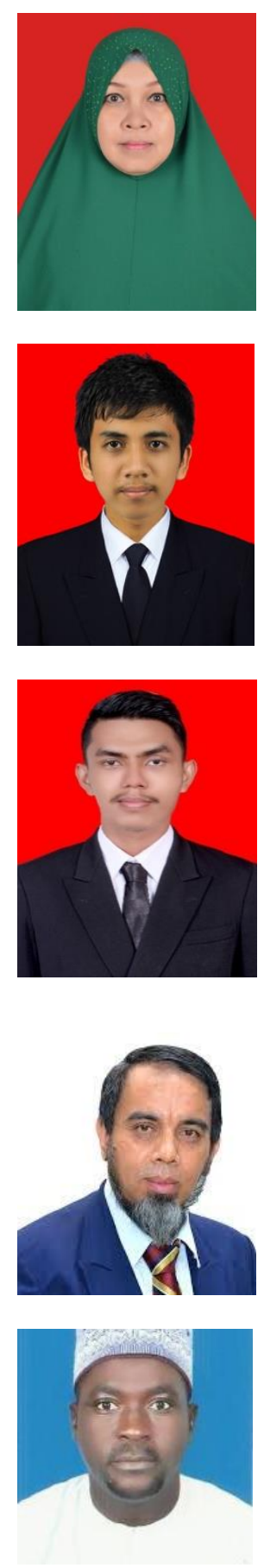

Azriyenni Azhari Zakri received a Bachelor's in Electrical Engineering from Universitas Bung Hatta, Padang, Indonesia, in 1998. The Master's and Ph.D. in Electrical Power Systems from Universiti Teknologi Malaysia (UTM), Johor Bahru, Malaysia in 2007 and 2017 respectively. Since 1999, she has been a lecturer in the Department of Electrical Engineering at Universitas Riau, Pekanbaru, Indonesia. Her research interests include Power System Protection, Energy Conservation, Smart Grid, PMU measurement, Energy Storage, and Intelligent Techniques.

Syukri Darmawan received a Bachelor's degree in the Department of Electrical Engineering from Universitas Riau, Pekanbaru, Indonesia, in 2018. His research interests include Power System Analysis, Software Engineering, and Intelligent Techniques.

Sandy Ahmad received a Bachelor's degree in the Department of Electrical Engineering from Universitas Riau, Pekanbaru, Indonesia, in 2019. His research interests include Power System Analysis, Software Engineering, and Intelligent Techniques.

Mohd Wazir Mustafa received his B.Eng in Electrical \& Electronics (Hons) (1988), M.Sc Electrical Power Eng (1993), and Ph.D. in Electrical Eng. (1997) from the University of Strathclyde, Glasgow. Currently, he is a Professor, and also Chair of School of Electrical Engineering, Faculty of Engineering, Universiti Teknologi Malaysia, Johor Bahru, Malaysia. His research interests include Power System Stability, Deregulated Power System, FACTS, Power Quality, Power System Distribution Automation, and Smart Grid.

Jafaru Usman acquired his B. Eng. (Hons) in Electrical and Electronic Engineering in 2004 and M. Eng. in Electrical Power Systems in 2011 from the University of Maiduguri, Borno State, Nigeria. He received his Ph.D. degree in Universiti Teknologi Malaysia. His current research interests include Power System Stability and Control, Optimisation Techniques in Power System Control. He is a member of IEEE. 